\title{
URBAN SYSTEMS
}

How can a parametric Building Information Model serve to democratize, optimize and challenge the master planning process at Carleton University?

\author{
by Peter Akiki
}

A thesis submitted to the Faculty of Graduate and Postdoctoral Affairs in partial fulfillment of the requirements for the degree of

\author{
Master of Architecture
}

Carleton University

Ottawa, Ontario

(C) 2016, Peter Akiki 


\section{Abstract}

Carleton University Campus is an example of an isolated institution with a masterplan to direct the growth of undeveloped space - the currently used 2010 masterplan is a projected snapshot of fifty years for that space. This thesis project explores the visualization of real-time datasets and how it might redefine the process of designing built assets for Carleton University campus. A parametric masterplan of the campus would present a flexible alternative to the current static ideal re-planned every five years. Proposed is a parametric visualization of datasets from which challenging decisions may be guided by accurate digital representations of real-world information. Presented are techniques in parametric scripting to create a Building Information Model (BIM) of the Carleton University campus embedded with information on infrastructure, people and energy consumption. A parametric BIM of Carleton University campus can exist as a detailed resource of information and statistics that parallel the operation and development of its physical counterpart.

The project explores the potential for parametric virtual representations of datasets to narrow the distance between the digital and the material world. It questions the implications of built assets on campus, results of which can be used as input parameters to create a feedback loop that further improves the datasets. Furthermore, the parametric masterplan can be used to compare simulated results with proposed real-world scenarios to help predict positive or negative impacts on Carleton campus. The goal of this parametric visualization is to democratize a variety of real-time datasets to the community at large so that they may establish quality proposals for the campus. 


\section{Acknowledgements}

This thesis could not be possible without the support of the students and faculty at the Azrieli School of Architecture \& Urbanism. I would like to thank my supervisor Steve Fai for his guidance throughout my studies at Carleton University and for the advice he shared with me during the development of this thesis.

As for the contents of this paper, I am indebted to the writers, Kristel Derkowski and the writings cited at the end; without them this work may not have been realized. 
Abstract

Acknowledgements

Table of Contents

List of Illustrations

Chapter ONE

The Campus Master Plan

ONE.1 Carleton University

ONE.2 An Urban Proposal

ONE.3 Parametric Master Plannning

Chapter TWO

Collaborative Urban Development

TWO.1 BIM

TWO.2 Drawing Beyond Construction

Chapter THREE

The Urban System

THREE.1 A Virtual Place

THREE.2 Up-To-Date Information

Chapter FOUR

Majority Thinking

FOUR.1 Democratized Space

FOUR.2 A New Perspective

Appendices

Appendix A

Bibliography

Citations 
Figure 1 Physical model of North Campus

Figure 2 Brainstorming during Campus Master Plan conference

Figure 3 Statistics obtained from http://carleton.ca/about/facts/ Graph obtained from 2010 Campus Master Plan

Figure 4 Digital Campus Innovation

Figure 5 Methodology

Figure 6 Pedestrian traffic 


\section{ㅁints}

集社

回目的的

Illustration 2 BIM of urban datasets

口我品

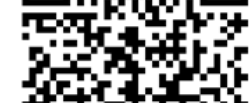

位子

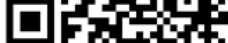

Illustration 3 Isovist archive

Illustration 4 Density map

Illustration 5 Foot traffic data

口+1:

104

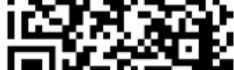

Illustration 6 DEM/Topography

Illustration 7 Polylines for virtual geometry

Illustration 8 Isovist analysis

四

$7+4$

解

口.thes:

Illustration 9 Urban systems scale


Illustration 12 Urban BIM

口ir

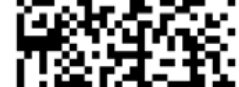

回蛙

Illustration 13 22-AA Char

का

被数;

Illustration 14 Carleton University campus Chart - by Level

Illustration 15 Carleton University campus Chart - Class Schedule 


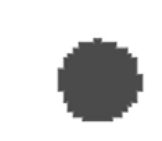

- 


\section{CHAPTER ONE}

\section{The Campus Master Plan}

"For any material object to obtain freedom is for its handler to lose control of it, and that does not happen."

$$
\text { - Robin Evans, Drawing to Building }
$$




\section{ONE.1 Carleton University}

Carleton University commissions the production of a Campus Master Plan that defines the strategies and standards for the physical development of the campus - its buildings, infrastructure, landscape and traffic systems. These masterplans are static ideals of a new campus based on up-to-date information and philosophies that might help shape a better place. The Board of Governors' policy requires the university to produce an updated version of the masterplan every five years even though the plans might propose a static model projected tens of years into the future. The Campus Master Plan is a document of principles and two-dimensional visualizations from a three-dimensional computer model. Currently, this three-dimensional model is not parametric and does not respond to the change in needs of Carleton University. A parametric three-dimensional Building Information Model (BIM) would be a flexible alternative that could direct the development of the campus with philosophies outlined by architects in tune with the needs and wants of the Carleton community.

Carleton University campus is situated on sixty-two hectares of land in Old Ottawa South and is categorized as an I2- Major Institutional Zone. ${ }^{i}$ While there is no limit to the height of built assets in this category, past Carleton masterplans have suggested a height no greater than six stories for new construction. This is because of the insufficient time it takes for students to travel vertically between their scheduled classes. The current campus buildings allow about ten minutes walking distance from one end of the campus to the other which is sufficient time for students traveling to and from academic programs. The organization of traffic routes, both pedestrian and vehicular, are a major part of The Campus Master Plan, and yet the university holds no archive of foot traffic on campus - this information is not recorded at all. To collect data on student/faculty movement through campus, designers schedule a single conference to question the community, generally resulting in subjective information about student arrival and destination routes around campus. A conference was held on campus on November 11th, 2016, to gather feedback from faculty and students about the 2016 masterplan. ${ }^{\text {ii }}$ Carleton University has commissioned Brook McIlroy to prepare the updated plan; their team includes a variety of designers, transportation planners and engineers. The Board of Governors will provide the final approval on the plan. 


\section{ONE.2 An Urban Proposal}

The 2016 Campus Master Plan proposal for the north end of campus also focuses mainly on the alteration and addition of traffic routes. ${ }^{\text {iii }}$ It intends to maintain the sufficient ten minute travel time for students by suggesting built assets of non-academic program on the North property, such as parking, residence, and community space. On January 18th, 2016, Carleton University hosted an open house at Minto 2000 Bell Theatre to present a draft of the new masterplan update ${ }^{\mathrm{iv}}$.There, associates from Brook McIlroy and Darryl Boyce, Assistant Vice-President of Facilities Management and Planning responded to concerns from the Carleton community, related to the draft. The majority of concerns were concentrated on traffic flow, travel times, vehicular (automobile and bicycle) and pedestrian routes and organization/orientation of proposed infrastructure. Out of approximately 31,046 people who work, live, study and visit Carleton University campus, less than 40 attended the open house, and only a handful fuelled the discussion - mostly faculty. According to Brook McIlroy, about 135 people responded to an online questionnaire about the 2016 Campus Master Plan. ${ }^{\vee}$ Engagement from the Carleton community in important hearings/surveys that impact the development of campus infrastructure is low compared to the total population. It may be that the current methods by which statistics, comments and other data are collected is outdated; the medium or interface used to analyse Carleton University could be improved to better democratize the process and include the full population rather than just a sample of it.
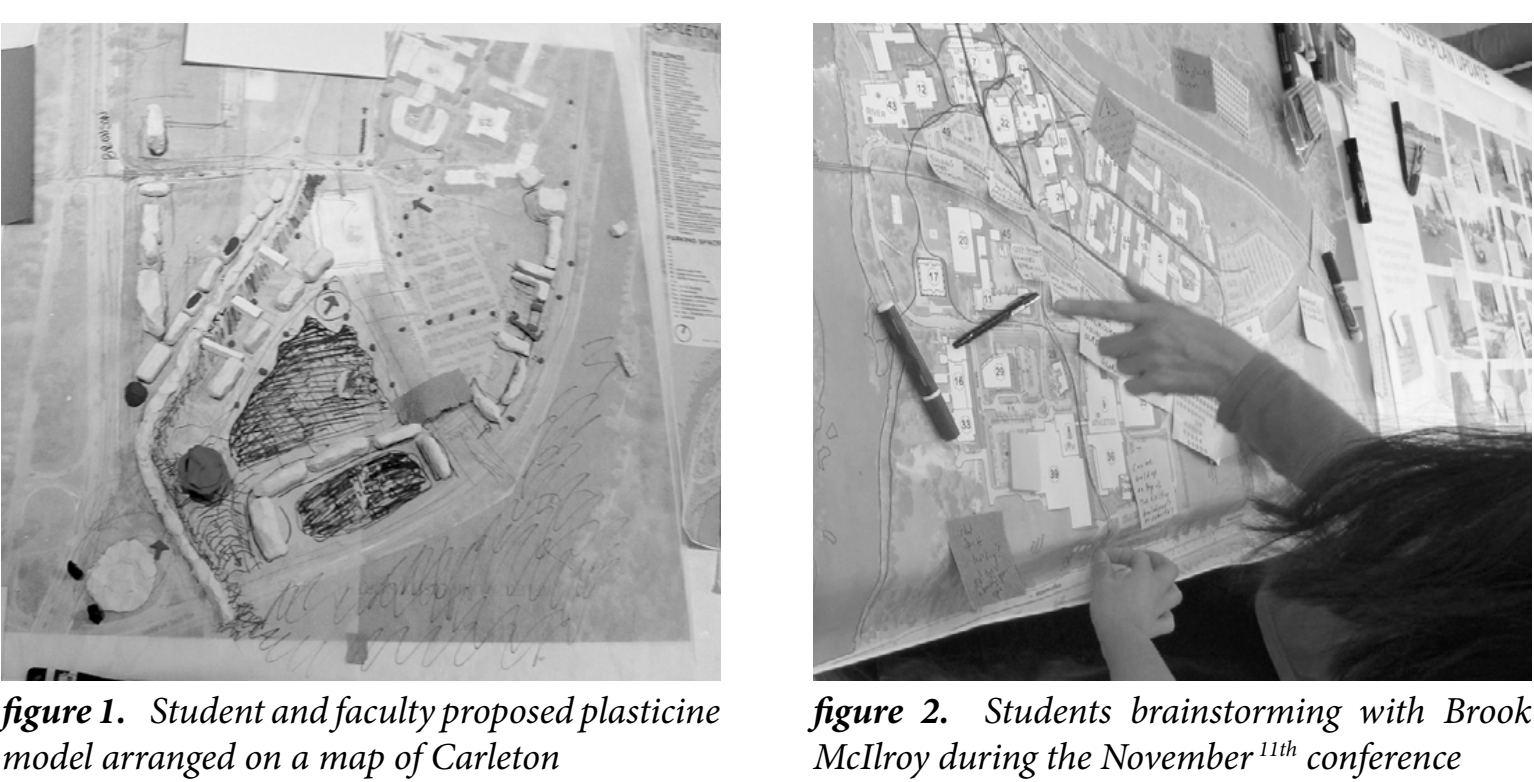
model arranged on a map of Carleton 

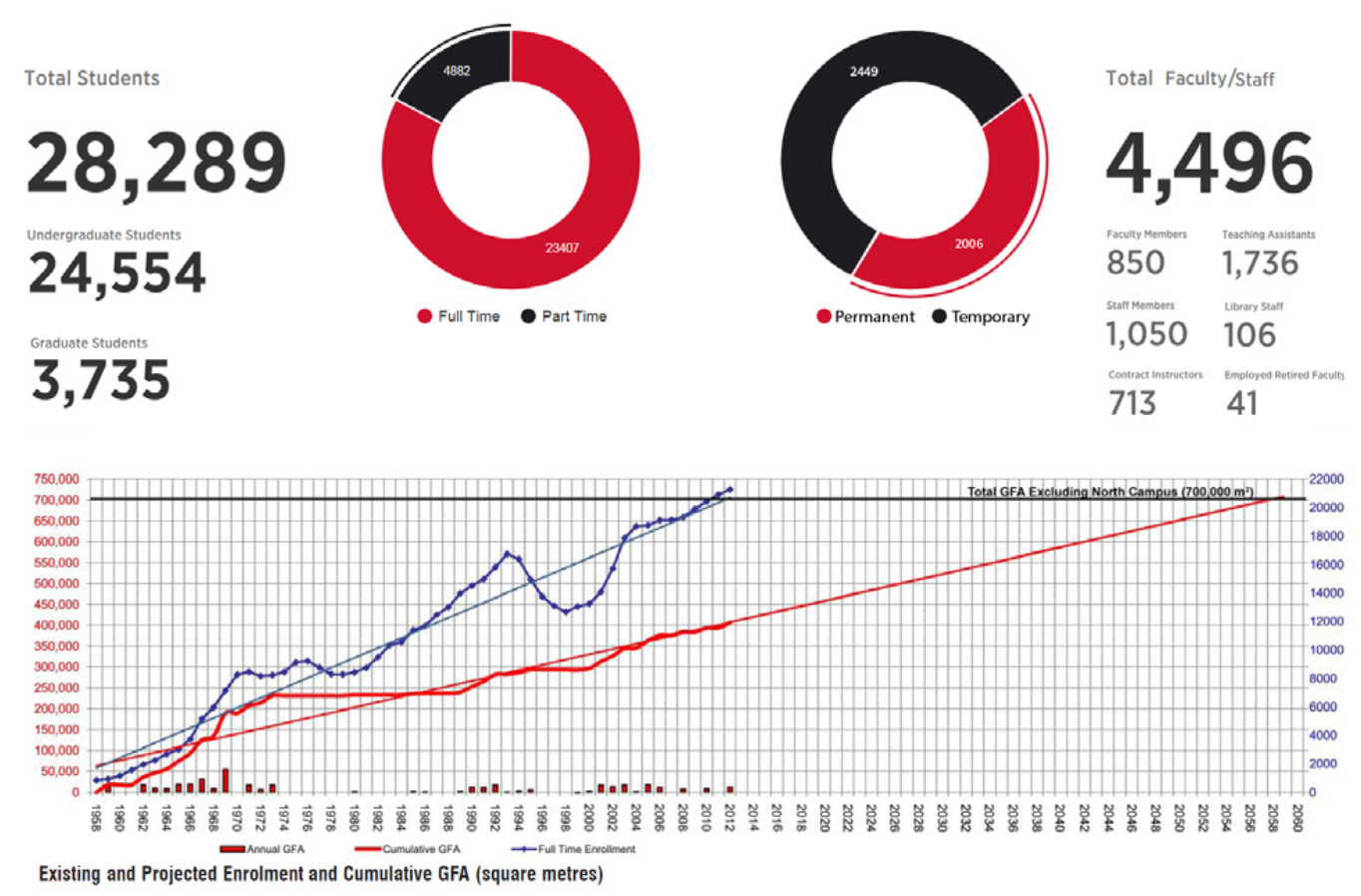

figure 3. These statistics show the current (20/03/2016) student and faculty population at Carleton University. The graph - obtained from the 2010 Campus Master Plans - shows existing and projected (linear regression) student enrolment (blue). It also shows the

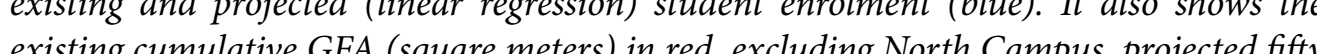
years into the future. It is important to note that this linear regression is s projected fift) dynamic situation.

Over the last ten years, the student body has grown by eighteen percent and the number of courses offered has risen as well - new programs have increased by thirty-eight percent. ${ }^{\text {vi }}$ The need to update the process of master planning to better incorporate all of Carleton University population is increasing. This thesis proposes ways in which a parametric Building Information Model could update the current process of master planning on Carleton University campus - and elsewhere. This BIM could relieve the Carleton University community of the five year gap between complete Campus Master Plan documents. It could be built with real-time, up-to-date objective data of Carleton campus and could be networked to be available to the full population of campus occupants. This would give students, faculty and researchers the opportunity to observe concurrent and ongoing philosophies, proposals and other data that develops on campus. 


\section{ONE.3 Parametric Master Planning}

A parametric model of Carleton University campus could present advances in the use of software by combining various methods of virtual representation of real-world information for architectural practice. These real-world datasets could include campus foot traffic patterns, occupant density, and social polls. This thesis project sets up a framework on which the master planning process at Carleton University can use current technology with proposed techniques to involve people in the development of the campus - a parametric master planning process to challenge decision-making. Campus development can be made better transparent and available, allowing the input of anyone and everyone who invests time into the campus to help dictate its built assets, philosophies, and program. This new parametric BIM could establish a condition where the proposed campus coexists virtually, simultaneous to the physical place - replacing the need for a static Campus Master Plan.

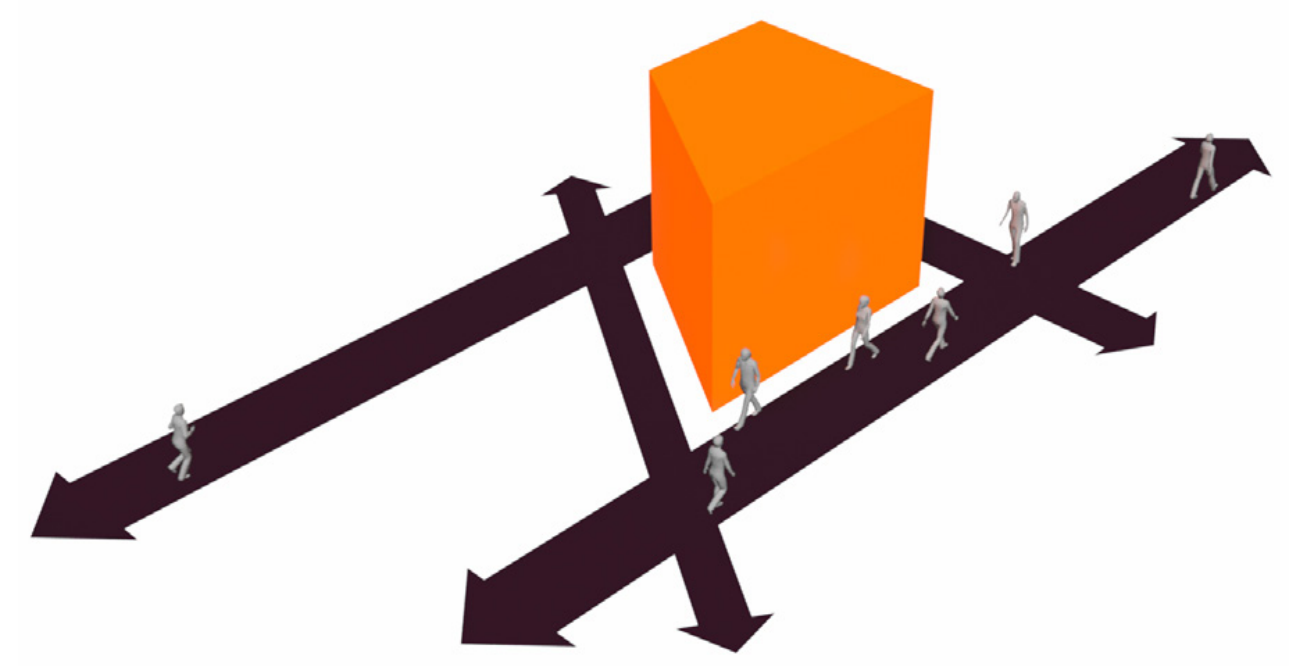

illustration 1. Screen-capture showing a parametric shift in pathways based on pedestrian density. A link to this visualization is provided at the bottom-right of this page.

Carleton University campus would benefit from a varying model that fits with the dynamic growth of the institution. Datasets of human phenomenon can influence the form finding in architecture through the interface by which Building Information Models are developed. Form finding in response to human activity can be adopted in other situations beyond this case study (at Carleton University campus) so that other places might benefit from a dynamic master planning process. The methodology set out in this paper is proposed specifically for Carleton University but could be considered for other large scale urban planning projects elsewhere. 
CHAPTER TWO

\section{Collaborative Urban Development}

"The public realm is like parentheses that hold together the differences between people." - H. Frei and M. Böhlen, MicroPublic Places 


\section{TWO.1 BIM}

A Building Information Model (BIM) can exist as a detailed resource of information and statistics that parallel the operation and management of its physical counterpart; BIM files can be shared and networked to unite decision-making from around the world. This paper develops strategies for creating a parametric BIM using the Autodesk ${ }^{\circ}$ Dynamo (version 0.9.1) plugin for Revit ${ }^{\oplus}$ Architecture 2016 and the Grasshopper (version 0.9.0076) plugin for Rhinoceros ${ }^{\circledR}$. A parametric Carleton University Campus BIM is the framework on which simulation and analysis could influence campus operation and development.

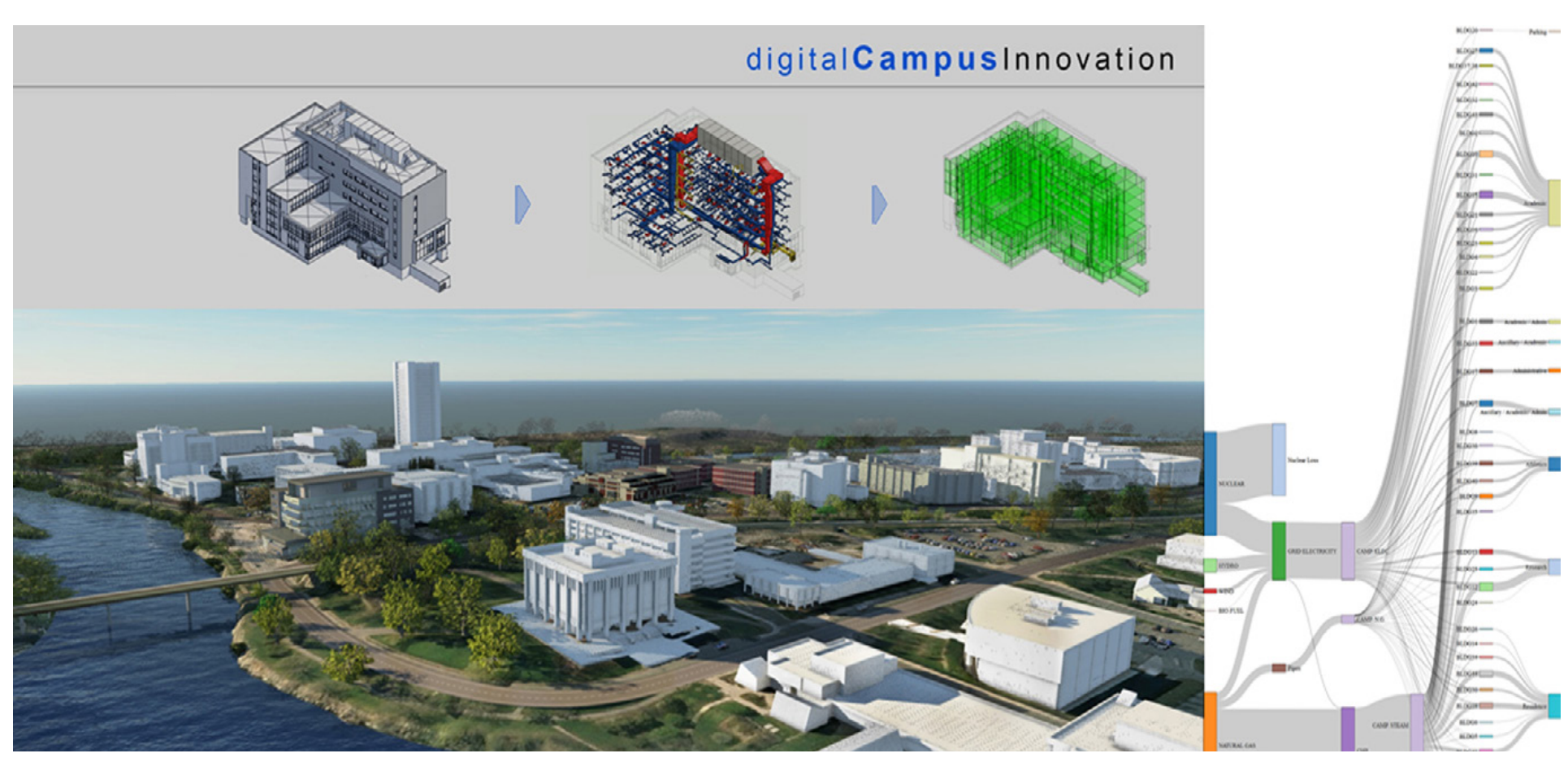

figure 4. A project that was organized in collaboration by the Carleton Immersive Media Studio (CIMS) and the Human-Building Interaction Lab at Carleton University. This Building Information Model of Carleton campus buildings is produced to include building systems - mechanical and electrical - with the intent that Facilities Management and Planning could virtually maintain and operate these systems. Engineering students Aly Abdelalim and Zixiao Shi, in charge of building performance simulations, used the datasets in the BIM to derive results on building energy efficiency. 

interface - a multifunctional representation of datasets with the ability to filter one with another categorically in orthographic and perspective views. Tools in BIM software allow users to define solid and void geometry as well as parametric constraints that could inform users of restrictions such as property lines and construction limitations. BIM geometry are embedded with dimensions, materials, thermal values and other information that sources industry standard material dimensions and tables (for example ASHRAE) that comply with Building Code specifications. Each model can be organized with views and schedules that provide values, cost estimates and product tracking and replacement. Building Information Models are useful tools in the professional practice where efficiency is important. They reduce the loss of information when distributed between architects, engineers, contractors and the owner/operator - saving time and money. Carleton University would benefit from the latter qualities of BIM if it were adopted as the primary method by which the Campus Master Plan is generated and distributed, but this thesis would like to provide further strategies that could improve the development of space with site-specific datasets. 

discipline-specific geometry, often industry driven, and to recognize that for architects and urban planners, who organize space for human use, those geometries in virtual space are rarely visualized with (instantaneous, up-to-date) feedback of human phenomenon. Datasets of human phenomenon, such as traffic flows, and social polls could further and better inform the decision-making that coordinates the composition of boundaries, area, height, and territory of countries and programs - public or private.

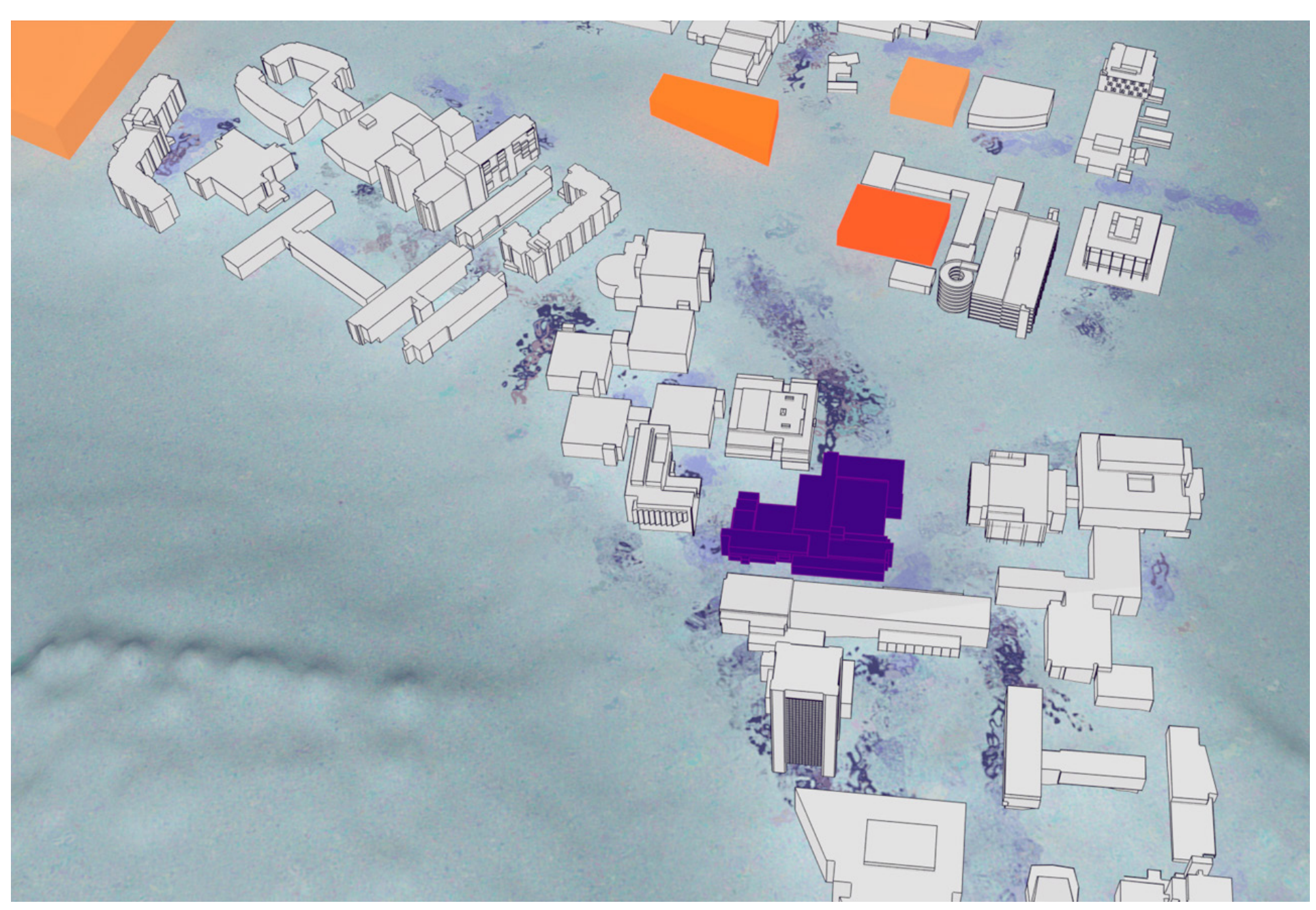

illustration 2. Screen-capture of an animation depicting a Building Information Model with foot traffic zoning and social datasets. The possibility of filtering through various combinations of these datasets - at different times of the day, month and year - provides the ability to visualize new patterns of information. A link to this visualization is provided at the bottom-right of this page. 


\section{TWO.2 Drawing Beyond Construction}

The relationships between BIM geometry are arbitrary unless otherwise defined by parameters, and in the case of organizing space, architects and urban designers are free to assemble objects to their desire - as they should be, unrestricted by the software. However, geometry in BIM is often organized without feedback from datasets of human phenomenon and this paper proposes that the addition of this type of data could help improve the decisionmaking process for designers. Visualizing this type of information can also begin to broaden the use of BIM in architecture because it establishes a feedback relationship with occupants to improve a design progressively. In his book, Persistent Modeling, Phil Ayres writes "Herbert Simon defines design activity as the devising of 'courses of action aimed at changing existing situations into preferred ones'. If applied to a timeline in which preferred situations become existing situations, the logical conclusion must be that design should be re-iterated in the light of new preferred situations, thereby accommodating but also instigating further change. This defines a circular and iterative relationship which should persist. This kind of persistence is not novel to architectural design if modelling is considered as a continued and progressive engagement with design questions. However, in relation to the realization of design proposition, design activity is not generally pursued indefinitely."vii A Carleton University campus BIM - updated with real-time datasets that reflect the physical growth of the campus - could be an iterative design tool when the simulated data from built assets are used to progress the algorithms that define the parametric model. It would provide Carleton University with a non-linear device that could be used to identify new proposals for built assets year after year and replace the current master planning process. This situation would counterbalance Phil Ayres' statement where he recognizes that "once the design proposition has been realized...it eclipses the active role of representation; it no longer maintains a directly transformative capacity, and the realized no longer holds a tentative and provisional status in relation to the body of representation." ${ }^{\text {viii }}$ Unlike the current Campus Master Plan, a parametric master planning model would maintain an active role in representing preferred situations. In this process, the architect's conception is no longer a linear progression to the 


\section{CHAPTER THREE}

\section{Urban System}

"Mobile phone and Internet networks open up new ways for publics to organize themselves. These media can be used as territory devices' to take possession of an urban public space." - Martijn de Waal, The City as Interface 


\section{THREE.1 A Virtual Place}

Commonly, in architecture, design proposals resolved through three-dimensionalcomputer modeling involve the manual arrangement of geometry (dimensioned to scale) rather than the generation of geometry through rules of computation. To do either of these, designers use a computer as their functionary - capable of computing complex mathematical algorithms. In this case, the computer is the apparatus as per Giorgio Agamben who states, "[an apparatus is] anything that has the capacity to capture, orient, determine, intercept, model, control or secure the gestures, behaviors, opinions, or discourses of living beings. ${ }^{\text {ix }}$ Computer software/programs are then the rules that simulate human thinking, based on the scientific understanding of the world, and which then produce virtual, three-dimensional computer models used for simulation and analysis. As the thinker behind the Campus Master Plan, the architect should be responsible for coding the software, defining the algorithms and properties, calculated from scientific observations, which attempt to make three-dimensional models comprehensible for construction. The physical space of buildings and landscape are conceived by digital information that we collect, consume and organize through interface. The skillset of the architect would expand to include computer programming since it would provide him/her the ability to manipulate virtual geometry by a set of rules rather than just a set of dimensions. These rules could govern a virtual model and limit the geometry to boundaries and restrictions set by the architect. In this way, the architect's role has not changed but shifted to a new medium - his/her philosophies are translated into computer code. 


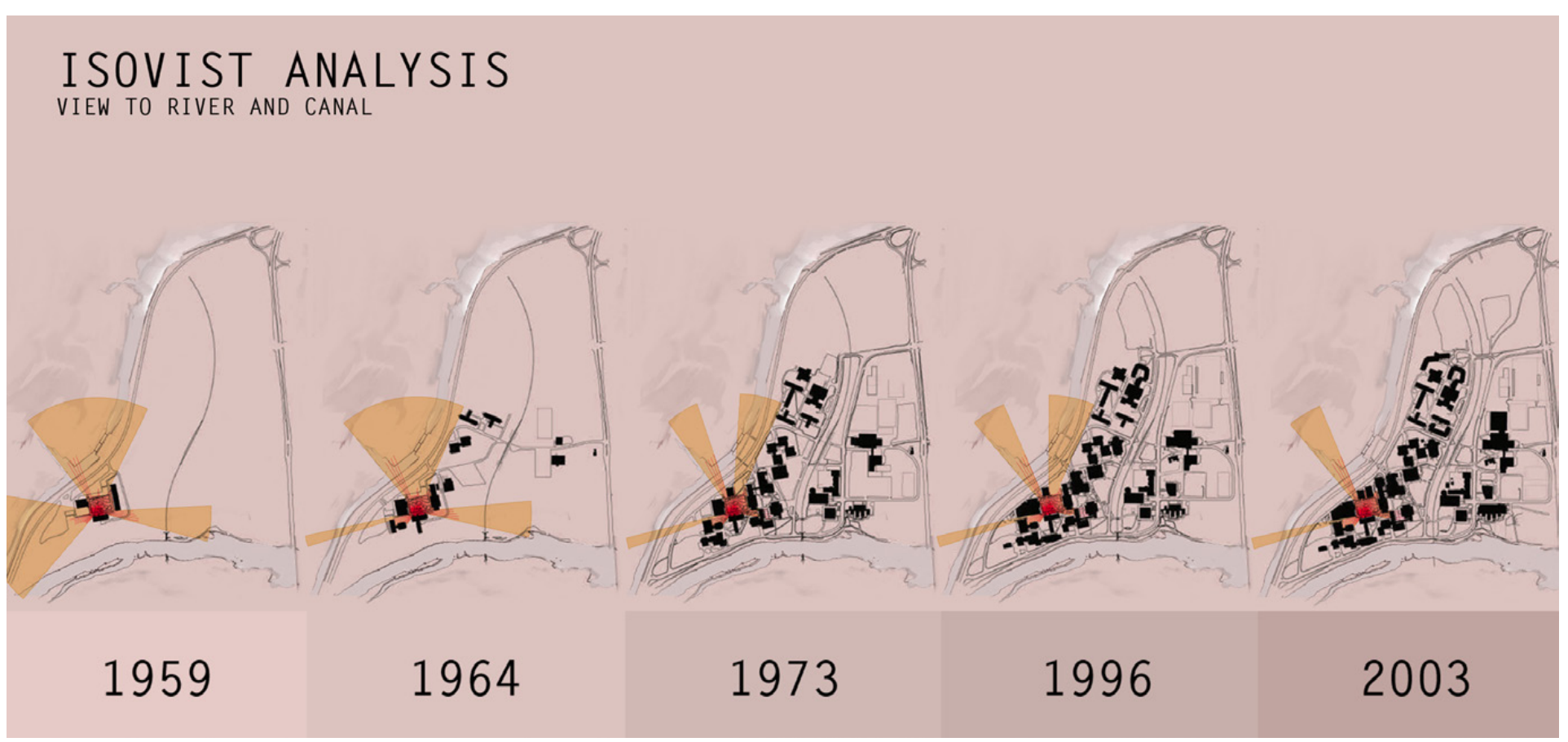

illustration 3. Isovist study in Carleton campus quad between 1959 - 2003 ; evidence that pedestrian view to the Ottawa River and Canal have reduced over years of development.

The image above illustrates an example of a parametric BIM that would provide evidence of change; a record of the history of phenomenon, proposals, and development. A record of data over time would allow designers and researchers to explore multiple combinations of visualizations and afford the observation of new patterns and configurations. 

of his/her decisions. These decisions, archived over time, could be used as input for the computational generation of virtual geometry; these geometry would be choreographed to move, scale, double, and rotate in three-dimensional space to respond to the datasets. This illustrates a condition where the computer software would generate a new masterplan algorithms that learn from the archive and predict the dimensions, connections, proximities, and material properties of geometry so as to construct proposals that adapt to the change in human phenomenon. These new masterplans are computer generated propositions that are limited by the philosophies which are input (as computer code) by architects and urban planners. Through computation, this thesis tries to illustrate how architectural drawings may exist past occupant use and begin to simulate future conditions of Carleton campus.

No longer does the masterplan represent a complete determination of proposals for a single future; each change in state can be assessed by the architect/urban planner to determine the relevance and effectiveness at establishing the desired philosophies set by The Board of Governors. This digitally crafted, cost-effective iteration of proposals is an ever updating parametric BIM that can be altered by computer code to redefine the rules that govern the reasoning for each variation. Visualizing the implication of proposed infrastructure on a virtual campus might be a more adapt and tangible tool to improve student/faculty feedback for Carleton University. From his book Drawing to Building, Robin Evans writes, “The drawing has intrinsic limitations of reference. Not all things architectural can be arrived at through drawing. ${ }^{\text {’xi }}$ Compared to the static Campus Master Plan documents, the parametric Building Information Model could reveal a new dimension in drawing through an interface that visualizes non-geometric conditions such as behavior and energy. It could also organize comments, suggestions and proposals in an interactive visualization that categorizes and archives user inputs for further analysis. 
Prerequisites for understanding Carleton University Campus as an urban system in this thesis are the behaviors of pedestrian traffic and topographic land use. Translating these physical behaviors into virtual space, using existing computer software, this project establishes visualizations that people can engage with to derive new patterns and combinations that better an urban system. Computer software has changed the activities we engage in each day, including the way we design built form. To customize form, separate from the biases of the programs we model in, we must write computer code to tailor our ideas in virtual space. Scripting has become a popular method of modelling architecture for its ability to execute the latter with the added support of a BIM environment (for example the Autodesk ${ }^{\bullet}$ Dynamo plugin for Revit ${ }^{\circ}$ Architecture). The scripts created in this project are found in the appendix; they relate to the collection, visualization and analysis of datasets from Carleton University campus. Although these scripts are specific to the datasets collected for this case study, they can be adopted for other urban planning projects when the inputs are changed. 
figure 5. The methodology used in this thesis to collect data and process it into meaningful information through various visualization techniques. This process describes a non-linear approach for creating drawings through computation - analyzing and refining visualizations to make information clear is important for the dissemination of knowledge.

To collect foot traffic data on Carleton University campus, as seen in figure 4, a camera was set at the twenty-second floor of the Dunton Tower to capture video of passersby below. The tower was chosen for its vertical height so that the camera may capture footage as orthographic as possible - the video is still orthographically rectified using editing software To analyze the pedestrian traffic flow, the video analysis and modeling tool Physics Tracker is used to locate the ' $\mathrm{X}$ ' and ' $\mathrm{Y}$ ' position of each passerby with the variable ' $\mathrm{T}$ ' for time. This information can now be processed by a script linked to a Microsoft Excel document. 


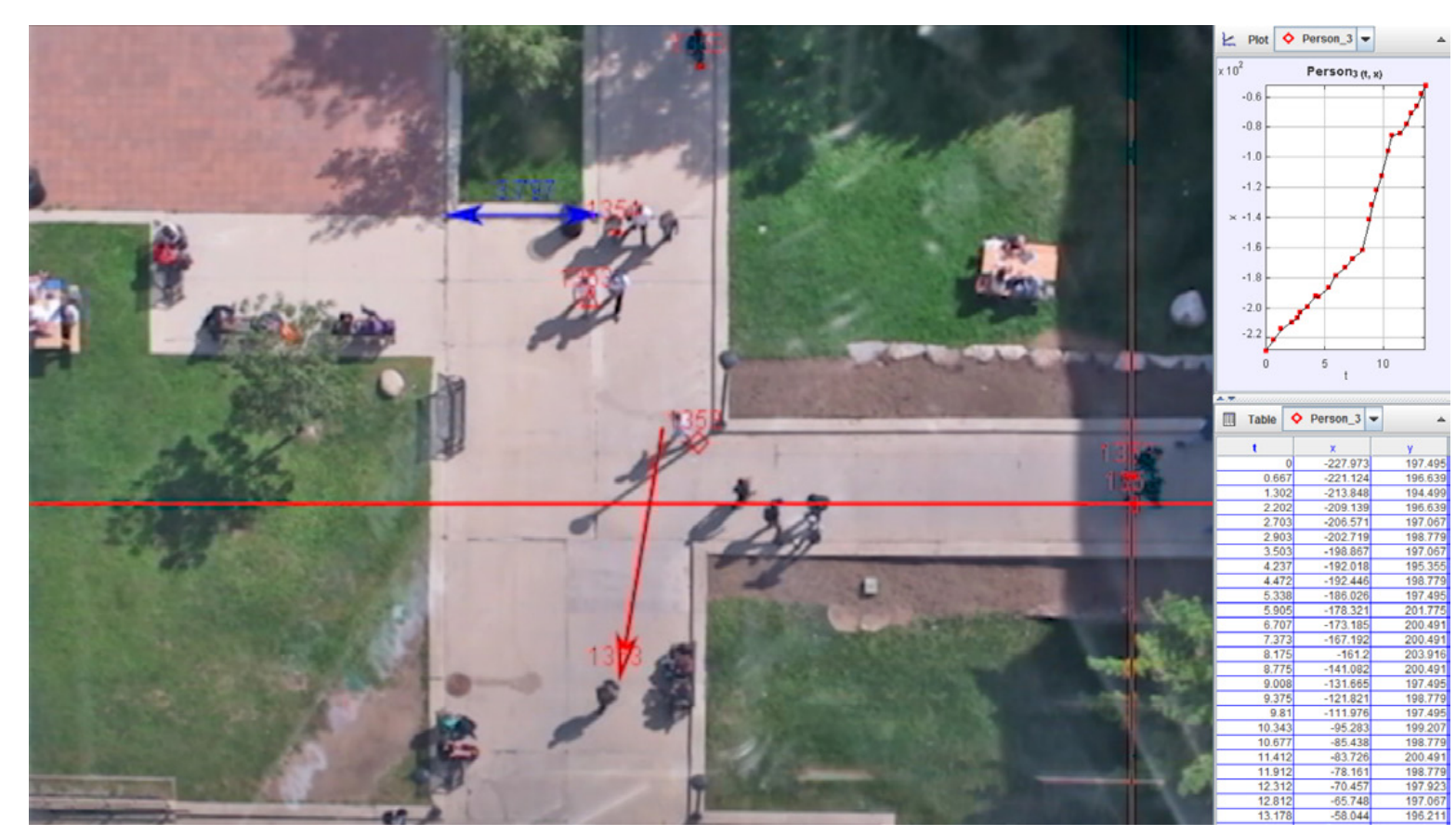

$\stackrel{m}{n}$

figure 6. Screen-capture of pedestrian traffic on Carleton University campus.

For the collection of foot traffic across campus, the previous section describes an experimental method that has since been outdated but that is still relevant for the script used in this project to visualize the data. Another method, suggested for foot traffic data collection, is through wireless device tracking. Since the majority of students and faculty that visit Carleton University carry a smartphone, it could be possible to locate the position of people on campus through geographic information system (GIS) applications that capture position of a smartphone - similar to the extraction of ' $\mathrm{X}$ ' and ' $\mathrm{Y}$ ' coordinates through orthographic videography. The advantage with a GIS application is that more information can be obtained, such as the arrival and destination points on campus, paths taken in the Carleton University tunnels, and positions inside campus buildings. All of this information can be combined into a dataset that could establish a network of travel routes and program locations. So, now a virtual system of academic and non-academic programs can be visualized with travel-time and proximity. This could help visualize new connections and that might improve the mobility, density and distances of pathways across campus. This technique of collecting pedestrian traffic data might also expand to communicate with vehicles with the emerging technology of the smart car. 

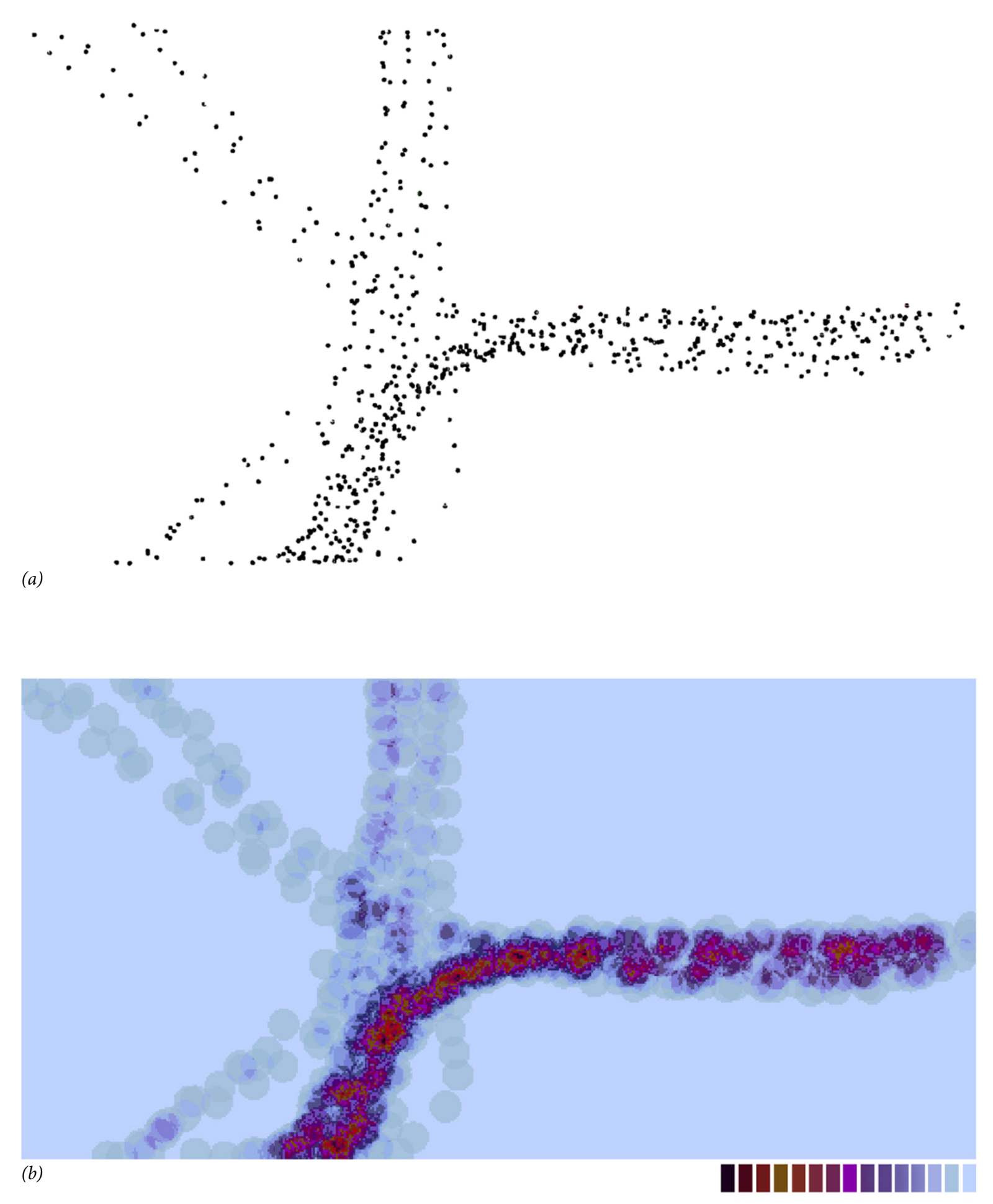

illustration 4. (a) Plan view of foot traffic as ' $X$ ' and ' $Y$ ' coordinates recorded over time. These points are plotted in a virtual, three-dimensional environment using Autodesk ${ }^{\circledR}$ Dynamo (version 0.9.1). (b) Density map created using ArcMap" (version 10.3.1) to illusstrate the concentration of pedestrian traffic. 


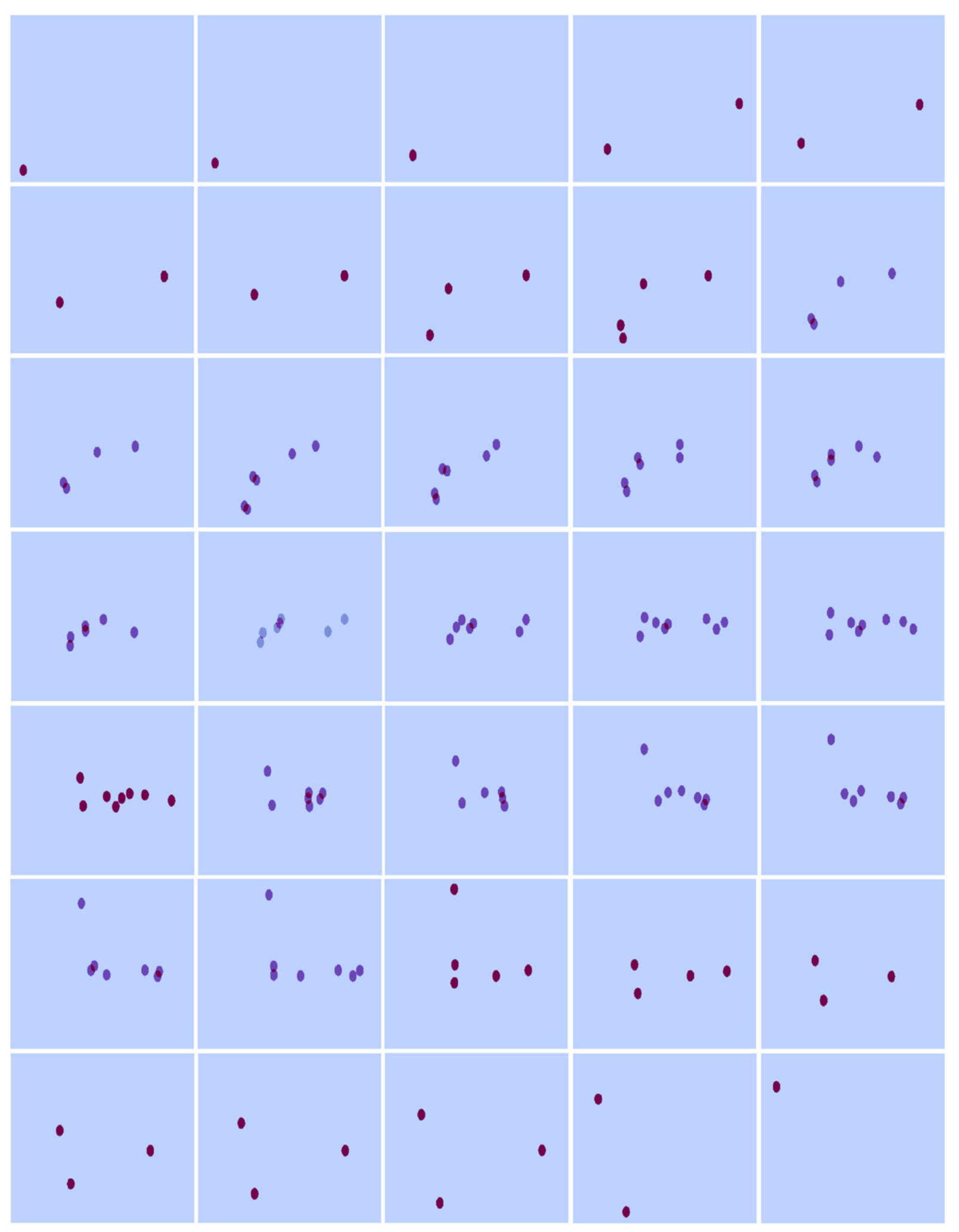

illustration 5. Screen-captures of animated points - showing the density of pedestrian traffic with respect to time. A link to this visualization is provided at the bottom-right of this page. 


\section{THREE.2 Up-To-Date Information}

Scripts are written to visualize foot traffic and geographic datasets. Using up-to-date input, the scripts developed in this project could potentially produce real-time visualizations of topographic and traffic information on the Carleton University landscape. In this project, shape files from National Capital Commission (NCC) LiDAR scans are processed to create a BIM model of the campus terrain. This is useful for the extraction of cross-sectional information and visualizing campus land use.
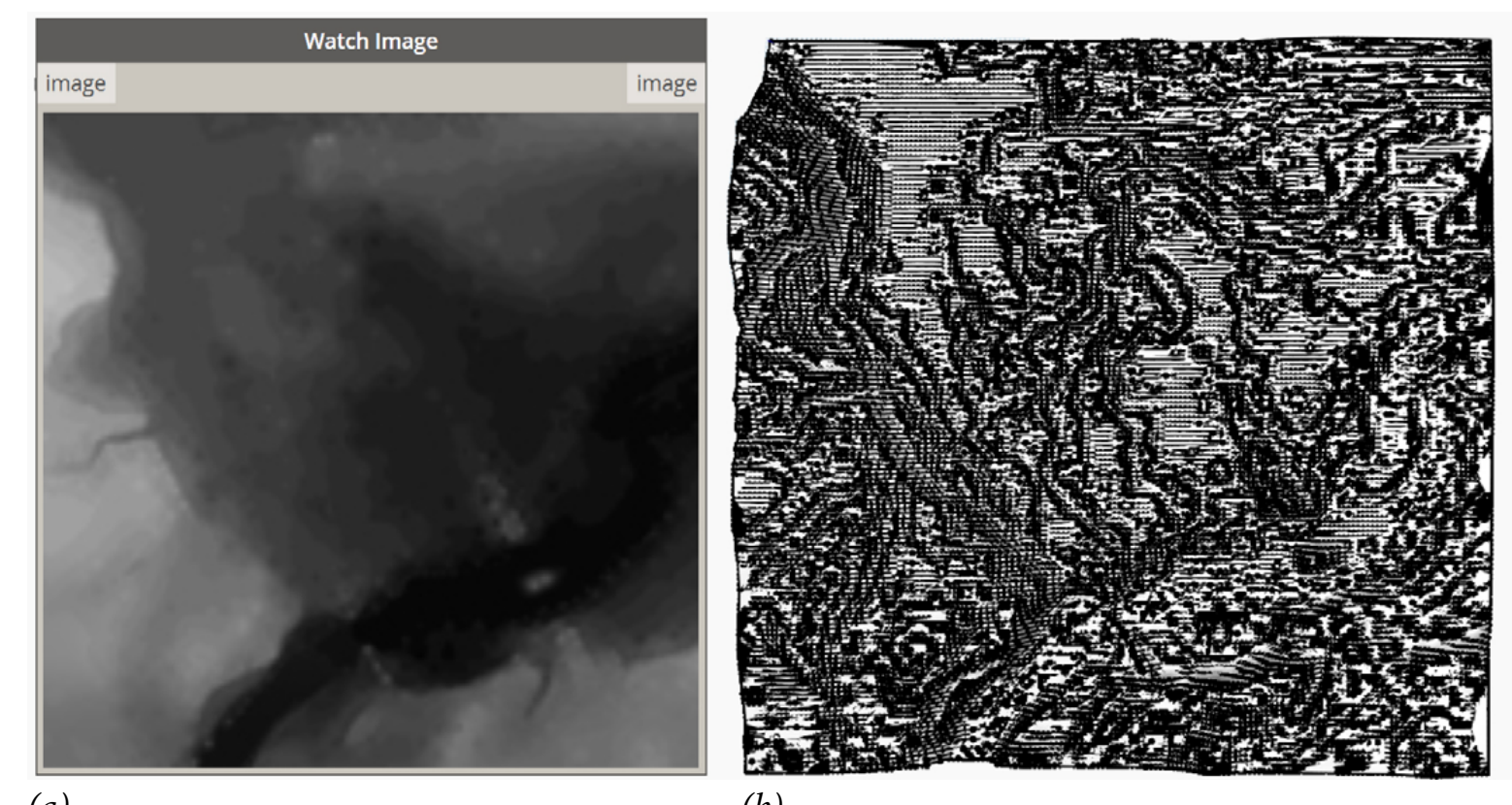

(a) (b)

illustration 6. (a) Digital Elevation Model (DEM) of Carleton University created from LiDAR scans obtained from the National Capital Commission (NCC). Values in brightness identify depravation where white denotes the highest $z$-value and black the lowest $z$-value. (b) Plan view of virtual geometry representing the topography of Carleton University campus. A higher resolution would create a more refined topography. 

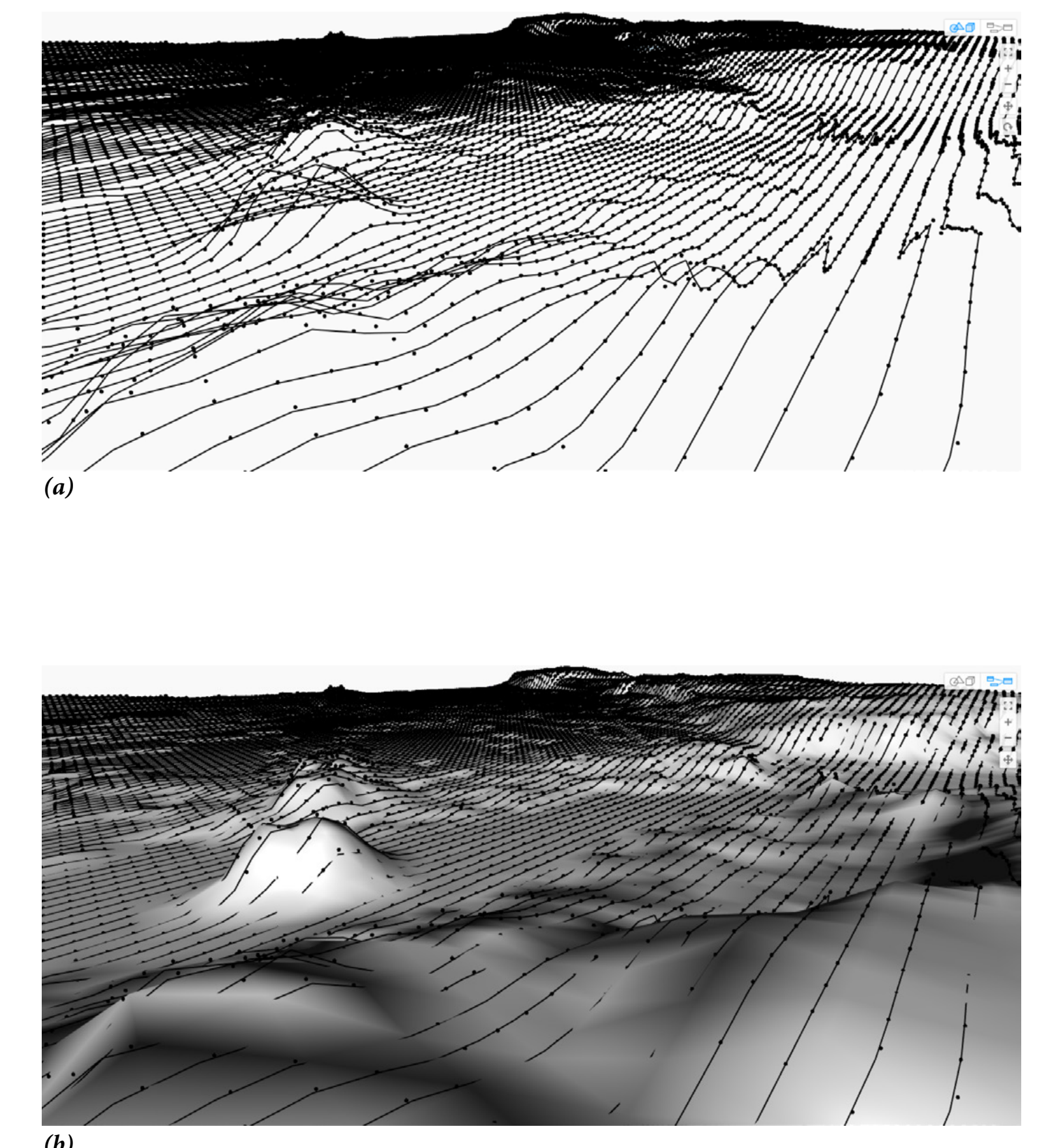

illustration 7. (a) Perspective view of polylines drawn (in a virtual, three-dimensional environment) through reference points. The reference points are positioned at $z$-values that refer to pixel brightness from a Digital Elevation Model (DEM). (b) Perspective view of virtual, three-dimensional geometry representing Carleton University campus landscape. 


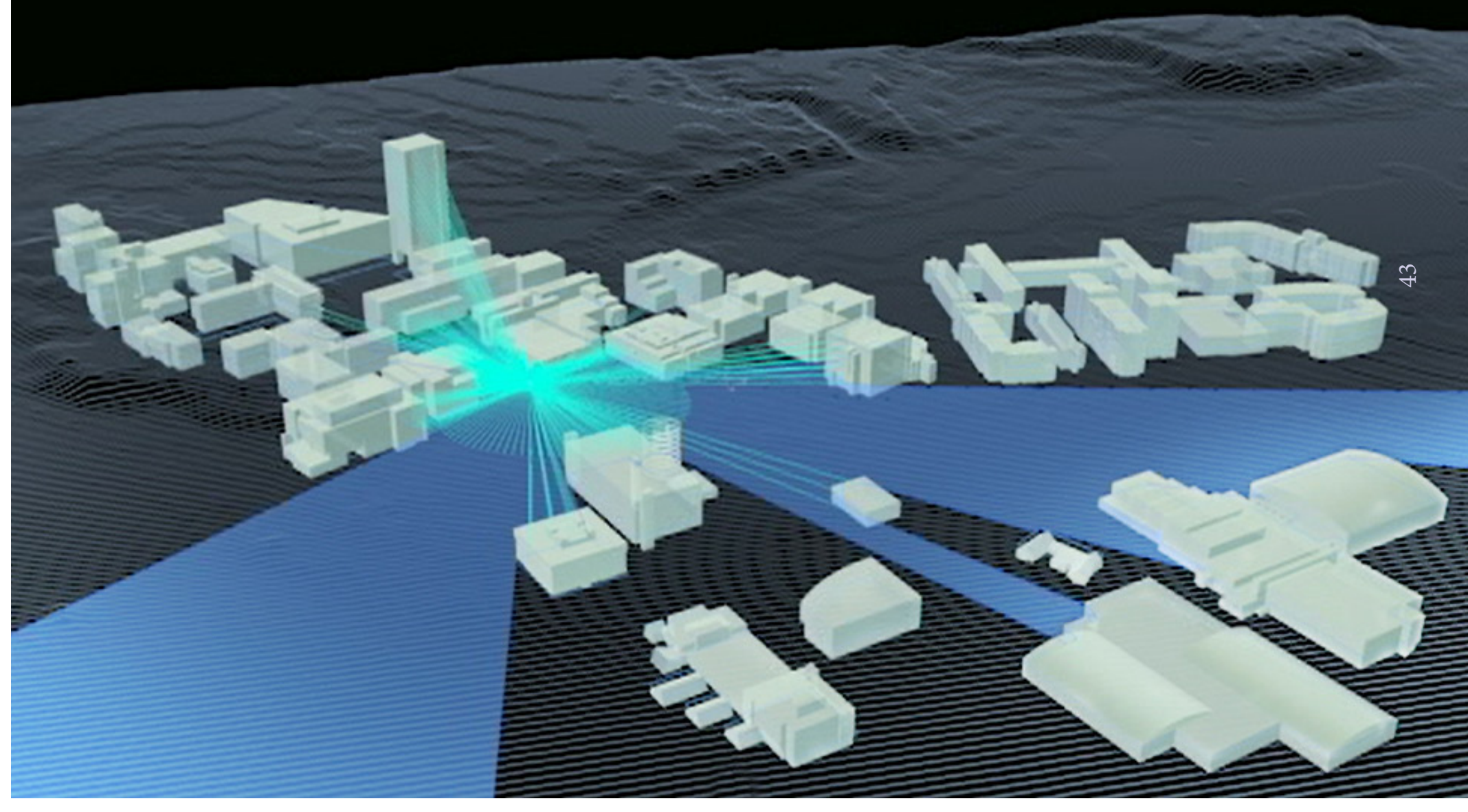

illustration 8. Screen-capture of a simulation analyzing the amount of view to the Ottawa River and Canal (bordering the campus). Access and view to the River and Canal have been specified (in the Campus Master Plans) as a major focus in organizing built assets for Carleton University. The algorithm used to produce this isovist analysis might help in regulating the development of the campus to better reflect the latter focus.

Simulations can also be used to imitate real-world processes and systems on campus over a period of time. In this project, simulation is possible to visualize pedestrian movement so as to explore future scenarios in campus infrastructure that might improve mobility or land use. The consequences of built assets can be visualized in a virtual space so as to assess the positive or negative impact of the proposal on the physical campus. A record of simulated results could be archived for comparison between different scenarios or scenarios projected over time - a documented evidence of change in development. 

is a big improvement from its predecessor, but it was implemented in 1997. Since then, the ways in which people access information is changing and communication through visualizations are increasing with new hardware inventions we see each year, such as the Apple Watch ${ }^{\circ}$, Oculus Rift ${ }^{\mathrm{TM}}$, Google Glass ${ }^{\bullet}$ and FitBit ${ }^{\circ}$. A large percentage of commerce, politics, and social interaction takes place over the internet, and action toward the development of a parametric Carleton University campus BIM is important to strengthen the accessibility and immediacy that students and faculty have to the information about the physical campus. It would benefit Carleton University to update the campus master planning process into a democratized virtual environment that encourages participation and the interrelationship of ideas.

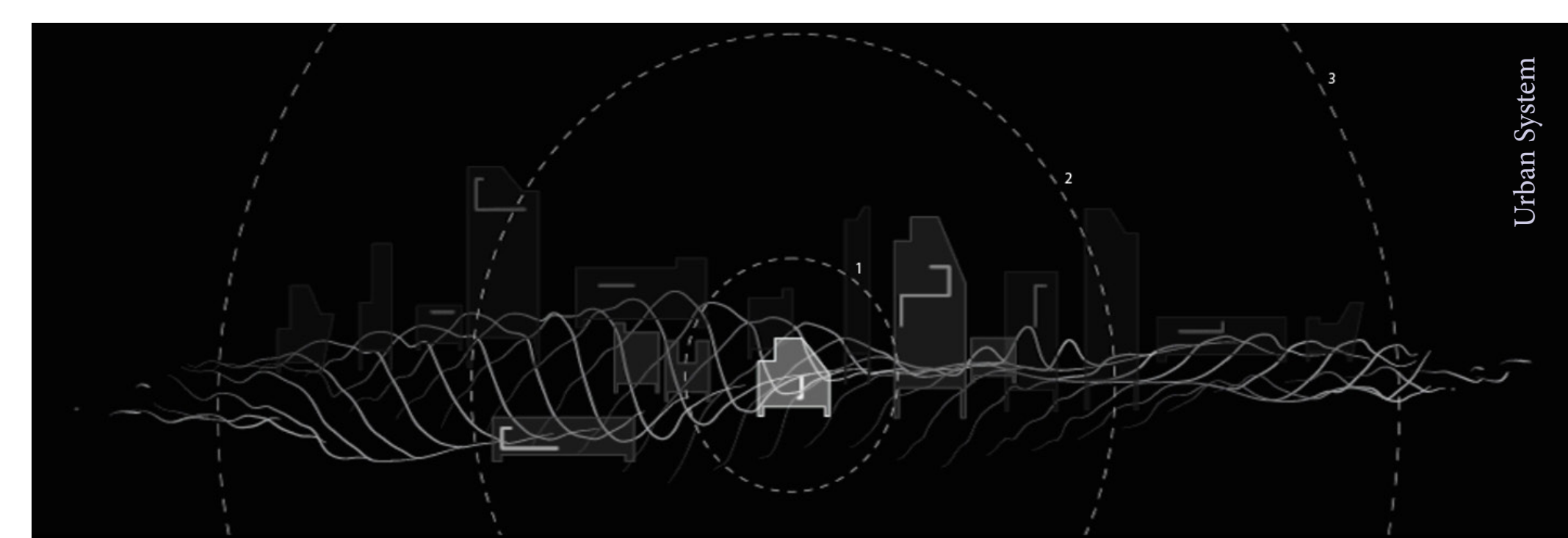

illustration 9. Systems can be visualized at multiple scales: (1) the building, (2) the campus, and (3) the city scale. The scale of this project focuses on the campus scale 


\section{CHAPTER FOUR}

Majority Thinking

"Designers stand between revolutions and everyday life." - P. Antonelli et al., Design and the Elastic Mind 


\section{FOUR.1 Democratized Space}

From this thesis, it is important to recognize that we cannot think about the virtual environment without addressing and understanding the computer code that manages these environments. With the latter perspective, we designers are not left at the mercy of the computer software, and our imagination remains free to design and organize space in this new medium, a virtual medium - relevant to the physical spaces we inhabit.

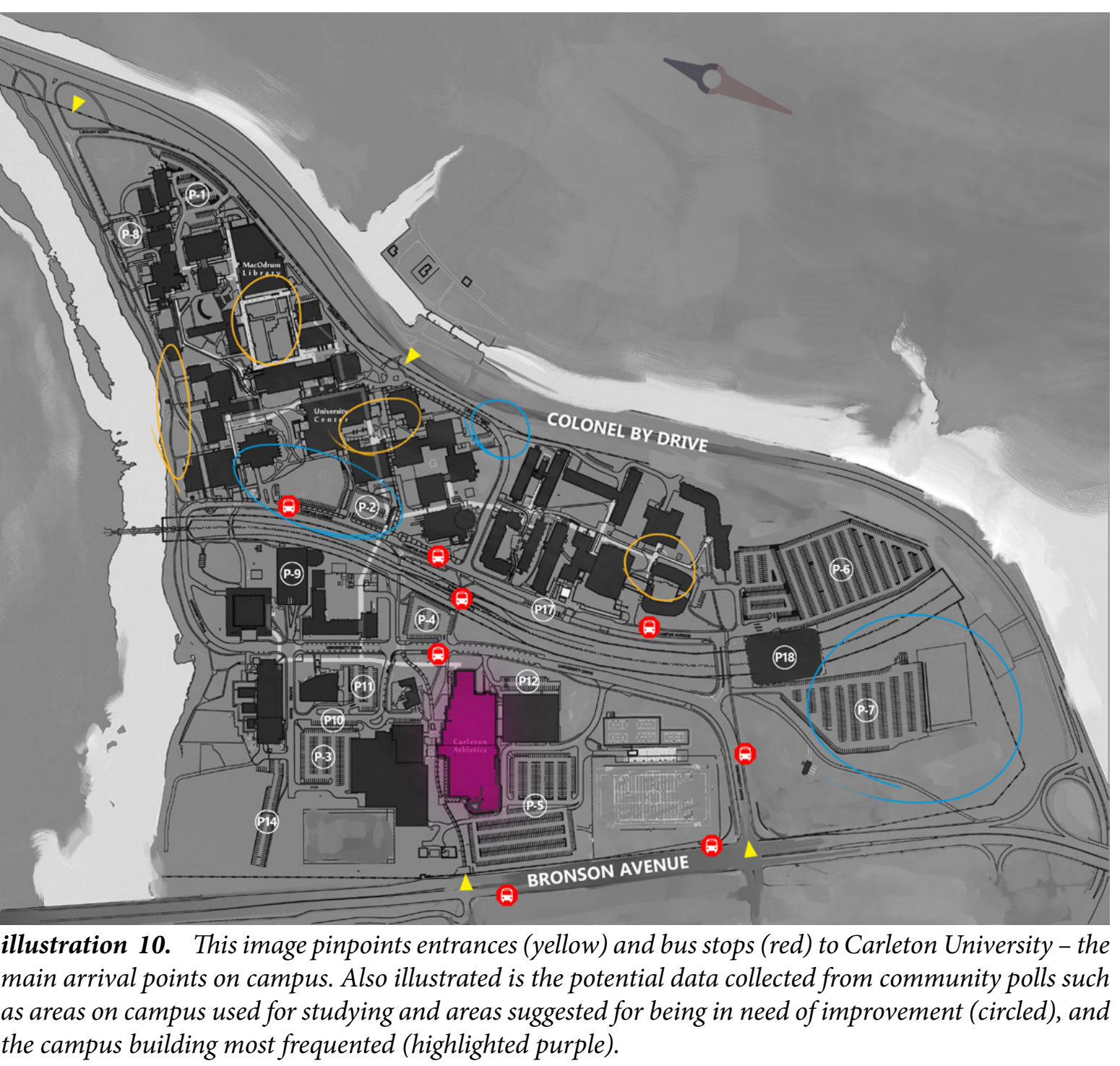


The Carleton University mission statement is: "To highlight, celebrate, and cultivate Carleton's expertise, leadership and collaboration with the community to create greater accessibility and a more inclusive world."'xii Using the ideas from this thesis, the process by which built assets are proposed for Carleton University would be updated to a single, democratized, three-dimensional environment - making it more accessible to the Carleton community and thereby increasing the potential for cross departmental collaboration and participation from students and faculty. The implementation of a virtual place to research, realize, and share ideas would extend the Carleton University mission to an accessible interface that illustrates the development of the campus. With this, the growth of the campus is driven by the participation of the people that inhabit the university - not from an exterior few that fail to speak for the many.

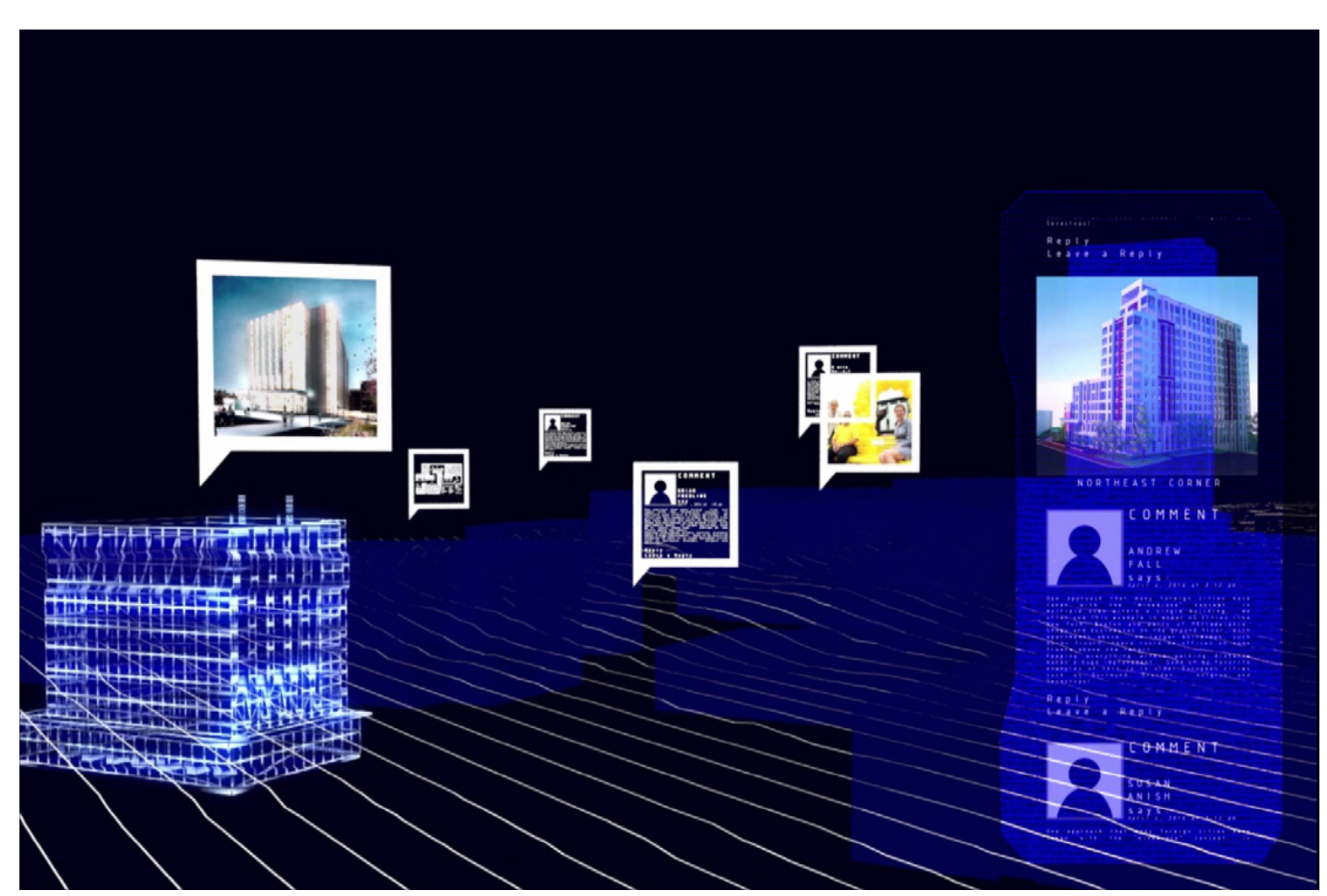




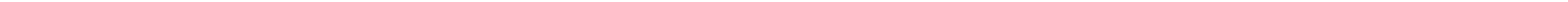




\section{FOUR.2 A New Perspective}

The democratization of space may not be limited to the buildings on campus. The datasets collected for the parametric BIM could be expanded citywide. Space for academic and non-academic program could be scheduled off campus - breaking down the physical boundaries of the built environment. The implications of new and different programmatic arrangements can be visualized through simulation and assessed in terms of feasibility. Below is a visualization presenting data on built assets - information that can be networked into an urban system.

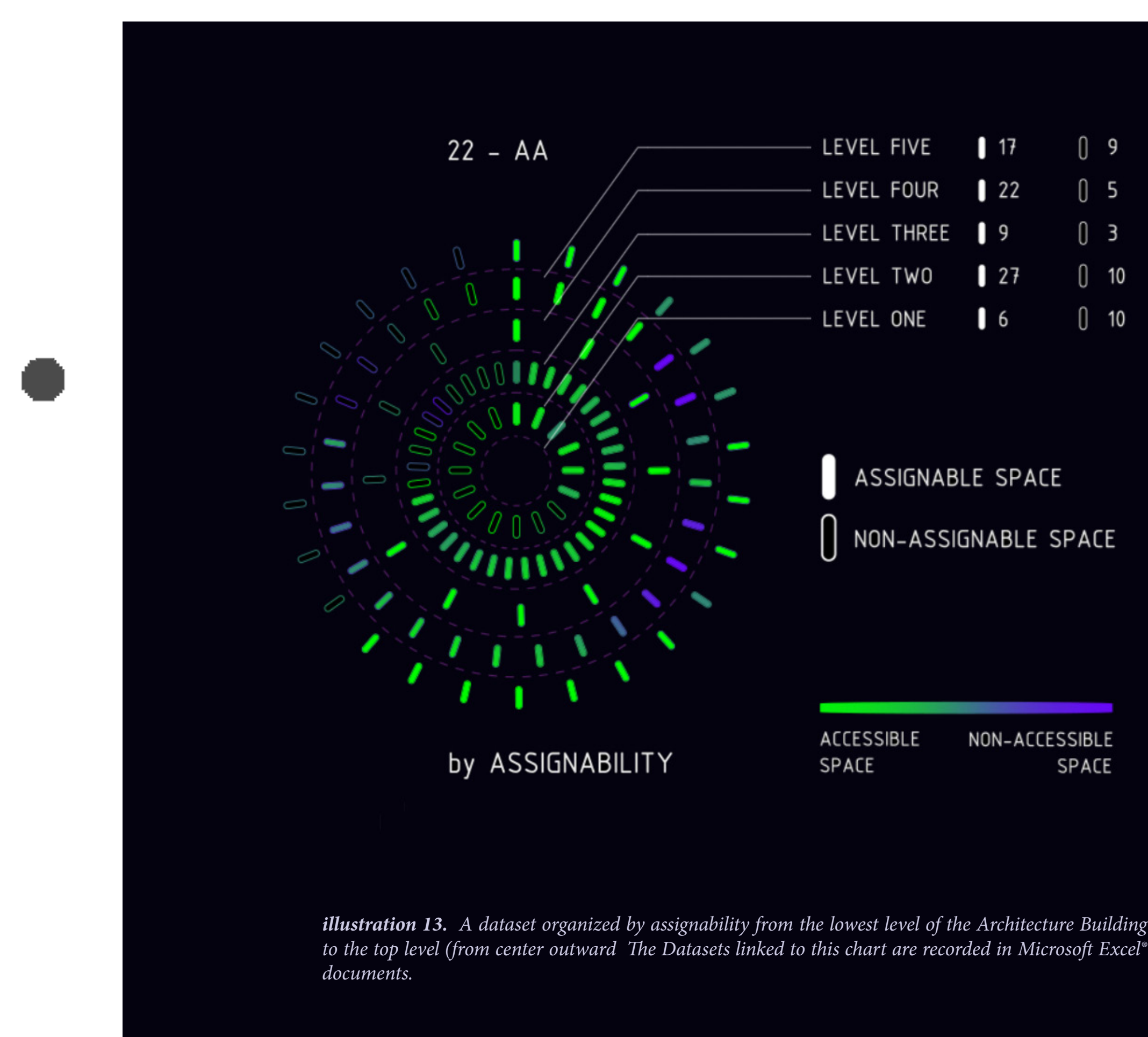


LEVEL TWENTYTWO
LEVEE TWENTY NEE

LEVELTWENTY ONE
LEVELTWENTY
LEVEN NINETEN

LEVEL NINETEEN
LEVEL EIGHTTEEN

LEVEL SEVENTEEN
LEVEL SIXTEEN

LEVELFIFTEEN

LEVEL FOURTEEN

LEVEL TWELVE

EVELLLEVEN
EVELLTEN

SEVEL

EVEL NINE

LEVEL EIGHT

LEVEL SEVEN

LEVEL SIX

LEVEL FIVE

LEVEL FOUR

LEVEL THREE

LEVEL TWO 


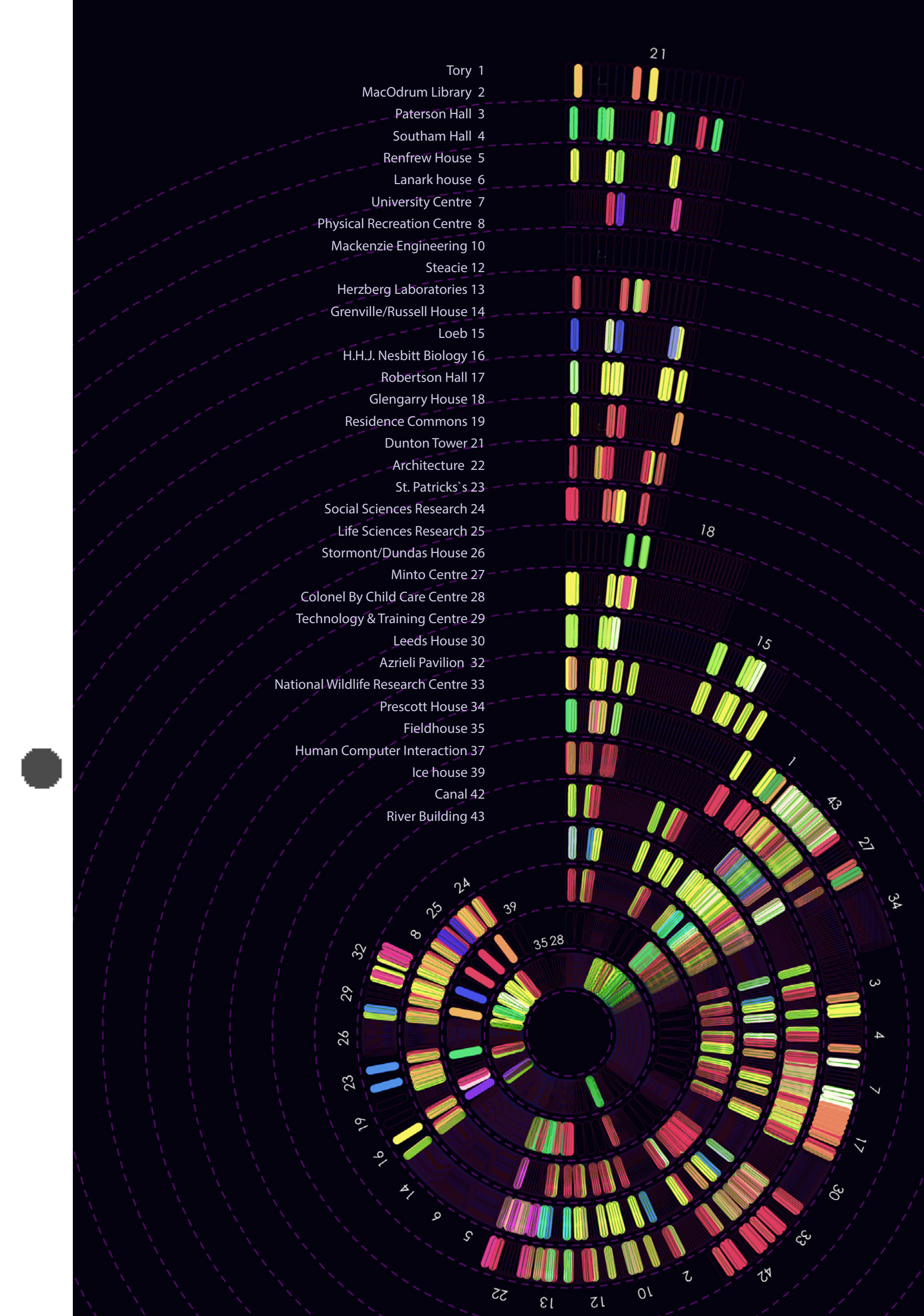


In architecture, collaboration is an influential part of the design process and as was for this thesis, which is why this project has tried to illustrate ways in which this can be done using new technologies, relevant for today. As Martijn de Waal writes, "Data visualizations of air quality, movement patterns, traffic rhythms, the collective use of resources and so on can make common patterns visible or provide insights into issues that concern the community as a whole: the collective level can be made visible as well the role played by individual city dwellers in creating or solving a problem."xiii Results from this project have been the successful scripting of individual datasets for real-time management - important in this thesis are the datasets of human phenomenon which define a major catalyst in the urban system. The way in which these datasets could be combined into a BIM is animated in a visualization that simulates their use. The visualization of these datasets is coupled with the design process so as to continually prompt thinkers with implications from their choices. A parametric BIM would provide Carleton University the financial relief from a recurring five year update of the Campus Master Plan; it might also establish in-house employment to govern the parametric BIM. The organized integration and record of social/occupant data would increase the feedback available for development, increasing the likelihood of positive change - fit for a majority. It is important to recognize, however, that the methodology set up in this project is not limited to Carleton University campus; the ideas of social/occupant data recorded in BIM to inform citizens of urban issues city-wide and influence collaborative design might also be applied to a large scale complex, city, or country. 
Built form is designed for the human in mind - to inhabit, or experience - but humans are unable to inhabit our designs until they've been realized and, by that time, it can be too late to reverse whatever conflicts built form may impact mobility, accessibility, appeal, capacity, vision, etc. In terms of the Campus Master Plan, designers disseminate two-dimensional drawings that try to depict a better condition for the campus. To justify drawings like these, the human figure is positioned in the architectural model - virtual or otherwise - for the designer to gather a sense of scale. Geometry is dimensioned around the figure to establish proper conditions for a comfortable, safe and enjoyable space based on the intuition of the designer, his/her education, the precedence they've researched and the building code criteria. This thesis proposes an architectural Building Information Model that doesn't just suggest human proportions but also presents and simulates human phenomenon, in real-time, so as to contextualize built form, and democratize space on Carleton University campus. I'm not suggesting that we eliminate a designer's intuition and experience from the process; I'm suggesting that the University implement an objective measure of urban systems (ie. foot traffic) combined with instinct to make better decisions.

This project uses computer technology to visualize a feedback loop between a designer and students/faculty, where the actions of student/faculty could reflect the outcome of built form in real-time - for positive change. Like tracks carved in snow, or a dirt path marked through grass, a virtual representation of foot traffic illustrates visual evidence of movement - in context, at an urban scale. This information is crucial for the decision-makers to develop meaningful proposals in a context that directly relates to the students and faculty on campus. 
Although this thesis paper does not directly discuss the potential risks to the sensitive student/faculty data collected for the parametric BIM, it does debate the benefits of the dissemination of these human driven urban systems which could influence the design of infrastructure that provides better mobility, livability, efficiency, accessibility, and navigability at Carleton University. This information would put a lot of responsibility on the University to manage a secure dataset, but it could be facilitated by data volunteered by students/faculty who understand that this information would help Facilities Management and Planning to regulate proposals that are meaningful for all of the thousands of students with diverse disciplines. The services used to collect data for master planning purposes fail to gather a wide-ranging sample of students and faculty that work and study on campus. This thesis project presented ways in which the Carleton University community could vote, comment, submit and choose the designs proposed for the campus, allowing designers to review and adapt student/facultyproposed ideas during the design phase. The aim here is to engage and empower a community to participate and be aware of the decisions that impact where they study and work, and potentially be responsible for the outcome of the built forms they will interact with and/or inhabit in the future.

This project has used computational algorithms to establish visualizations of complex systems, in which each step in the design becomes a series of instructions that can be evaluated, revised, and improved - a process that can be disseminated and repeated. The result is a parametric Building Information Model that becomes a framework for human designers to focus on composition and meaningful choices - computers don't detect new patterns and behaviours, humans do - and so, a Building Information Model with active systems would enable researchers and designers to find new combinations and relationships between existing datasets. 
It is difficult to anticipate every end-use of the parametric BIM suggested in this thesis because some visualizations presented are absent the data required to make meaningful connections. However, it may have been made clear that offering people the access to new (systems) information could provide more knowledge, more understanding, and more imagination - when people are offered knowledge, they can find solutions. As a University, this institution has a responsibility to engage in a more evidence based strategy to justify design proposals for the campus - contributing to the research and development of urban planning technologies. The BIM presented in this thesis would be a tool for Carleton University to investigate and optimize mechanical and electrical systems. For example, Facilities Management and Planning could use the BIM to identify which rooms students and faculty visit throughout each week so as to better regulate the energy distribution across campus - limited to occupied space, saving energy. The BIM could help inform the design of buildings and regulate the boundaries of public and private space. It could help schedule classrooms to accommodate students with disabilities or professors with special equipment needs. It could help identify locations suitable for emergency telephones, security cameras or lights. It could help designers reject or confirm hypotheses quickly and better democratize the master planning process for students and faculty. In the end, Carleton University would be able to archive a record of urban systems and the physical conditions of the campus over time and actually asses the effectiveness of the decisions and philosophies integrated on campus. 


\section{Appendix A}
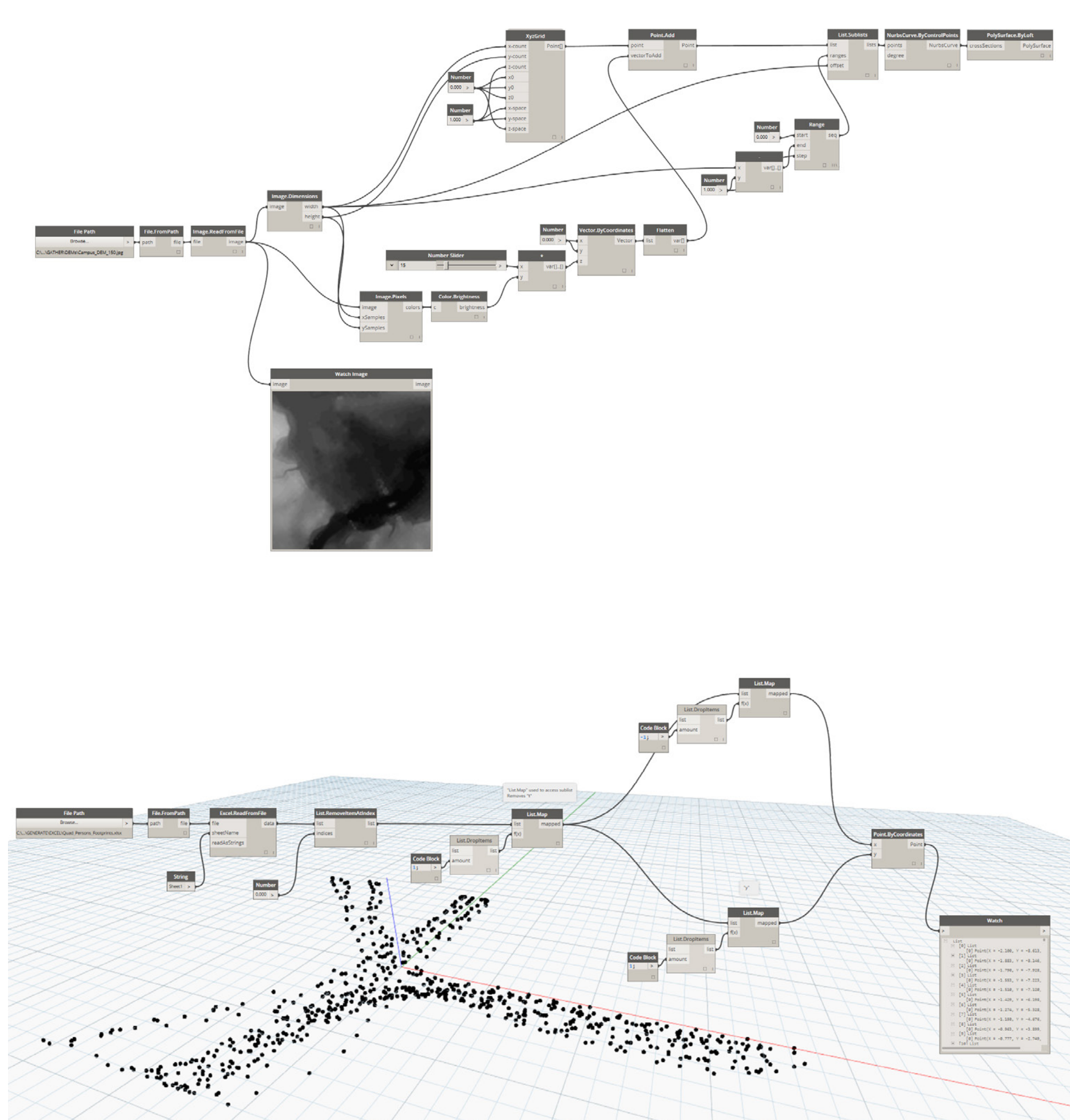


\section{Bibliography}

1. Mark Burry, Scripting Cultures: Architectural Design and Programming (Italy, John Wiley \& Sons Ltd)

2. Bob Martens and André Brown, Computer Aided Design (Netherlands, Springer)

3. Yasha J. Grobman and Eran Neuman, Performalism: Form and Performance in Digital Architecture (Spain, Routledge)

4. Martijn de Waal, The City as Interface: How Digital Media are Changing the City (Rotterdam, nai010)

5. Giorgio Agamben, What is an Apparatus?: And Other Essays (California, Stanford University Press)

6. William Mackaness and Anne Ruas and L. Tiina Sarjakoski, Generalisation

of Geographic Information: Cartographic Modelling and Applications (Amsterdam, Cartographic Association)

7. Phil Ayres, Persistent Modelling: Extending the Role of Architectural Representation (London and New York, Routledge)

8. Robin Evans, Translations from Drawing to Building (Massachusetts, The MIT Press) 


\section{Citations}

GeoOttawa < http://maps.ottawa.ca/geoottawa/> October 2nd, 2015

ii Carleton Newsroom < http://newsroom.carleton.ca/2015/11/06/campus-master-planreview/> March 10th, 2016

Facilities Management and Planning <https://dl.dropboxusercontent.com/u/20828247/ OH\%20CMP\%20Presentation\%20CAPTIONED\%20FOR\%20WEB.pdf> March 10th, 2016

iv Facilities Management and Planning $<\mathrm{http}: / /$ carleton.ca/fmp/campus-master-plan/> March 10th, 2016

v Carleton University <http://carleton.ca/about/facts/> March 9th, 2016

vi Carleton University $<$ http://carleton.ca/about/facts/> March 9th, 2016

Phil Ayres, Persistent Modelling: Extending the Role of Architectural Representation (London and New York, Routledge)

viii Phil Ayres, Persistent Modelling: Extending the Role of Architectural Representation (London and New York, Routledge)

ix Giorgio Agamben, What is an Apparatus?: And Other Essays (California, Stanford University Press)

x Phil Ayres, Persistent Modelling: Extending the Role of Architectural Representation (London and New York, Routledge)

xi Robin Evans Translations from Drawing to Building (Massachusetts, The MIT Press) pg. 159

xii Carleton University (http://carleton.ca/read/about-read/mission-statement/)

xiii Martijn de Waal, The City as Interface: How Digital Media are Changing the City (Rotterdam, nai010) pg. 175 